\title{
A Defence of Lucretian Presentism
}

\author{
Jonathan Tallant ${ }^{\mathrm{a}}$ and David Ingram ${ }^{\mathrm{b} 1}$

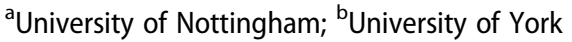

\section{ABSTRACT}

In this paper, we defend Lucretian Presentism ('Lucretianism'). Although the view faces many objections and has proven unpopular with presentists, we rehabilitate Lucretianism and argue that none of the objections stick.

\section{ARTICLE HISTORY Received 7 September 2018; Revised 12 September 2019}

KEYWORDS presentism; truth-making; Lucretianism

\section{Introduction}

Presentists believe that only present things exist [Adams 1986: 321; Bigelow 1996: 35; Ingram 2016: 2868]. That's not the whole story; there's more to say to flesh out presentism as a theory of time. Presentism is supposed to be a 'dynamic' theory: what's present really changes [Price 2011: 277; Miller 2013: 346; Leininger 2015: 726]. However, many focus on the ontological thesis, in isolation, when pressing objections. We defend a version of presentism that aims to meet objections to the ontological thesis. So, we won't elaborate a complete presentist metaphysic and won't worry about dynamism or passage, or anything of that ilk.

We review standard challenges to presentism and introduce the version of it that we defend, Lucretian Presentism ('Lucretianism'), a well-discussed yet unpopular view, from Bigelow [1996].

To introduce Lucretianism, we rehearse briefly the wider dialectic. Presentism is often described, by friend and foe, as the 'common-sense' view: it captures something important about pre-theoretic ideas about time-namely, the privileged present [Putnam 1967: 240; Butterfield 1984: 161; Bigelow 1996: 35-6; Sider 2001: 11; Markosian 2004: 48; inter alia]. Opponents insist that presentism has unacceptable implications: if only present things exist, they say, presentism appears undermined by a simple argument from relations. Bigelow [1996: 37] introduces the argument:

[For] a relation to hold between two things, both of those two things will have to exist. Call this the principle that all relations are existence entailing. Add as a further premise the supposition that relations sometimes hold between a present thing and something else which is not present. The conclusion follows ineluctably, that some things exist which are not present.

\footnotetext{
${ }^{1}$ The order of authors is arbitrary; both authors contributed equally to this paper. 


\section{More formally:}

(1) For a relation to hold between $x$ and $y$, both $x$ and $y$ must exist.

(2) Relations sometimes hold between some present and non-present things.

(3) Therefore, some non-present things exist. (From 1, 2)

(4) Therefore, presentism is false. (From 3)

The argument appears devastating.

But presentists aren't so easily undone. Although (1) and (2) are plausible, presentists will resist a modus ponens in favour of a presentism-preserving modus tollens and so will probably reject at least one premise. The presentist may say this: presentism is true, so there exist no non-present things, so not all relations are 'existence-entailing'. Or, instead, that presentism is true, and so there are no 'transtemporal' relations.

One premise must go, but which? Many think that we cannot abandon (1), and the principle that relations are 'existence-entailing', without abandoning good sense: that way lies madness, Meinongianism [Routley 1980; Hinchliff 1988], or nefarious presentism [Tallant and Ingram 2015]. ${ }^{2}$ Perhaps the only safe and sane route is to reject (2). But this takes us down a particular path. The anti-presentist argument from relations is succeeded by a more virulent iteration of the objection, which concerns truths about the past and truth-making. When explaining why he takes the initial argument to be pressing, Bigelow highlights his assumption that 'whenever something is true ... there must exist some thing or things in the world in virtue of which this is true' [1996: 38]. Every truth requires a truth-maker. The 'truth-maker objection' facing presentism follows simply from such considerations and is stated clearly by Armstrong [2004: 146]:

[What] truthmaker can be provided for the truth $<$ Caesar existed $>$ ? The obvious truthmaker, at least, is Caesar himself. But to allow Caesar as a truthmaker seems to allow reality to the past, contrary to [presentism].

The specific notion of 'truth-making' is understood, typically, as an existence-entailing relation between a truth (a true proposition) and a truth-making entity. In the case of truths about the past, this looks to be a transtemporal relation. The 'obvious' truthmakers for truths about the past are facts (states of affairs) involving past entitiesfor instance, the obvious truth-maker for $<$ Caesar existed $>$ involves Caesar, a past thing-and such entities must exist, contra presentism, if connected to the (true) propositions by the truth-making relation.

The question of whether the truth-making relation is existence-entailing (and thus whether it can be transtemporal without undermining presentism) isn't settled. Some presentists respond to the truth-maker objection by abandoning this thought. For instance, Tallant [2009] —who describes his view as 'cheating' - asserts that $<$ Caesar existed $>$ is made true by the fact that Caesar existed, but insists that this doesn't imply that non-present entities exist. For Tallant and others (for example, Sanson

\footnotetext{
${ }^{2}$ The principle that all properties and relations are existence-entailing is well-discussed and well-defended under the label 'serious actualism' ('SA'). For discussion and defence, see Plantinga [1983] and Stephanou [2007]. SA is discussed occasionally in connection with 'serious presentism' ('SP'). SA is expressed sometimes as 'no object has a property in a world in which it doesn't exist' which, arguably, follows from actualism (roughly, 'only actual things exist') [Bergmann 1996]. Similarly, SP ('no object has a property at a time in which it doesn't exist') arguably follows from presentism, the temporal analogue of actualism [Bergmann 1999]. If presentism implies SP, presentists cannot abandon (1); they must focus their critical attention on (2).
} 
and Caplan [2010]), the 'connection' between how things were (the past existence of Caesar) and how things are (the present truth of $<$ Caesar existed $>$ ) isn't an existenceentailing relation.

But perhaps such responses are misguided. Consider (for example) RodriguezPereyra [2005: 25], who argues that truth is grounded; that grounding is a relation; that relations link entities; and therefore that truth is grounded in entities. One who accepts truth-making on this basis will be unmoved by 'cheating' and, plausibly, unimpressed by arguments in favour of a 'nefarious' approach [Tallant and Ingram 2015]. Borrowing terminology from Tallant and Ingram, if the truth-making relation is existence-entailing, only an 'upstanding' approach will do: 'upstanding presentists look to provide truth-makers for truths about the past. Such presentists aim to meet the challenge head-on and provide the ontological ground required to 'make true' the relevant propositions about the past' [ibid.: 356]. One cannot meet the objection, so understood, without positing truth-making entities.

The 'upstanding' truth-maker objection can then be represented simply as an argument:

$\left(1^{*}\right)$ There are truths about the past.

$\left(2^{*}\right)$ Truths are 'made true' by some existing entity (entities).

$\left(3^{*}\right)$ Therefore, there exist 'truth-makers' for truths about the past. (From $1^{*}, 2^{*}$ )

$\left(4^{*}\right)$ The truth-makers for truths about the past are (merely) past entities.

$\left(5^{*}\right)$ Therefore, some non-present things exist. (From $3^{*}, 4^{*}$ )

$\left(6^{*}\right)$ Therefore, presentism is false. (From $5^{*}$ )

The options for upstanding presentists are limited. They cannot deny $\left(1^{*}\right)$-there are truths about the past-without abandoning good sense. Thus, upstanding presentists must deny $\left(4^{*}\right)$ : they must locate present truth-makers for truths about the past, and resist the idea that the only truth-makers are the 'obvious' truth-makers.

There is no shortage of upstanding presentists who posit present truth-makers for truths about the past (for instance, Keller [2004], Crisp [2007], Cameron [2011], McKinnon and Bigelow [2012], and Ingram [2019]). Our focus is on the canonical version of this strategy, Lucretianism [Bigelow 1996], which is well-discussed but unpopular.

The Lucretian metaphysic can be summarised as follows. The world-the 'totality of things' that exist (now)-presently instantiates a range of properties, expressed by tensed language, of the form 'having contained such-and-such' [ibid.: 46]. For Bigelow, within the context of a truth-making story, what exists to 'make true' any true propositions about the past is the world now instantiating the relevant 'tensed' ('Lucretian') property. The truth-maker for (for example) <there were dinosaurs $>$ is the world now instantiating the Lucretian property having contained dinosaurs, and so on.

Lucretianism has received a drubbing (for instance, Sider [2001: 37-42], Merricks [2007: 133-7], and Cameron [2011: 57-62]). Even Bigelow appears to abandon it [McKinnon and Bigelow 2012]. We go against the grain: we defend Lucretianism. ${ }^{3}$

\footnotetext{
${ }^{3}$ As far as we know, only McDaniel [2014] attempts explicitly to defend the view, but he focuses his attention on only a handful of objections. Our defence is more comprehensive. Tallant [2013] looks to undermine one main line of objection, concerning the respectability of Lucretian properties, but this defence of Lucretianism is partial. Others discuss and endorse, to varying degrees, views similar to Lucretianism that differ with respect to the nature of the properties or property-bearer (e.g. Chisholm [1990]; Keller [2004]; Crisp [2007]; Ingram [2019]).
} 
We don't motivate it, beyond noting that it offers presentists a way to address the truthmaker objection. Our task is defensive. Nevertheless, it's far from simple. There are myriad objections to Lucretianism in the literature. But none stick; so we argue.

In section 2, we deal with the concern that Lucretianism provides inadequate truthmakers, since truths about the past aren't 'about' (in a sense to be explored) the world instantiating Lucretian properties. In section 3, we tackle an argument from Sanson and Caplan [2010], that Lucretianism cannot provide 'proper explanations' of truths about the past. In section 4, we consider an objection, from Baron [2013a], which turns on the claim that Lucretians are forced to posit a relation between the present and past entities. In section 5, we deal with McKinnon and Bigelow's [2012] concern that there's an unexplained entailment between the properties that a present entity instantiates now and the Lucretian properties that it will instantiate. We also deal with a worry, from Orilia [2016], that some Lucretian properties involve a commitment to past entities, as the properties are specified by predicates that involve singular terms apparently referring to past entities. In section 6 , we reply to another objection from Orilia that Lucretianism doesn't provide truth-makers for dated truths about the past.

We don't deal with every objection to Lucretianism; we ignore those addressed elsewhere. ${ }^{4}$ Our aim is to defend Lucretianism from important challenges that haven't been well-addressed.

\section{Aboutness}

The first challenge says that Lucretianism provides inadequate truth-makers for truths about the past, since propositions about the past aren't 'about' present entities [Merricks 2007: 22-34, 136-42]. For instance, <there were dinosaurs > is about things (dinosaurs) that existed but exist no longer. Lucretianism posits present entities as truth-makers: presentist-friendly truth-makers are entities that exist now. For the 'aboutness'minded opponent, this won't do. There's a compelling intuition that truths about the past are about past things; and so we shouldn't endorse a view according to which truths about the past are made true by present things. Thus:

$\left(1^{\prime}\right)$ Past-tensed truths are about the past and not about the present.

$\left(2^{\prime}\right)$ If proposition $P$ isn't about the present, $P$ cannot have present truth-makers.

$\left(3^{\prime}\right)$ Therefore, past-tensed truths cannot have present truth-makers. (From 1', 2')

We argue that $\left(1^{\prime}\right)$ is false. To do this, we focus on Baron's [2013b] attempt to press the objection, which improves upon Merricks's presentation.

Baron [ibid.: 550] begins by articulating an aboutness intuition (AI): 'For any proposition $P, P$ 's truth supervenes on whatever it is that $P$ is about.' Then he states a pastness intuition (PI-About): 'True past-directed propositions are about the past.' Both are plausible. Since Lucretians posit present truth-makers (the supervenience base in AI), which aren't identical with past entities, Lucretianism faces an objection.

Baron claims that it's intuitive that past-tensed propositions are about the past and that Lucretian properties aren't identical with past entities. We agree. But we think that past-tensed propositions-namely, propositions expressed by sentences that include

${ }^{4}$ We agree with Tallant [2013] that Lucretian properties aren't objectionable because they are 'suspicious'. 
explicit syntactic past-tense markers-are, in fact, partly about the present. Although surprising, it's easily demonstrated. Compare two claims:

(a) The world is now such that it contained dinosaurs.

(b) The world was such that it contains dinosaurs. ${ }^{5}$

(a) is, intuitively, about the present. It makes a claim about how the world is now. It's (now) such that ..., where '...' is filled in with a predicate. Similar cases abound: 'Charles is guilty of having committed a number of heinous crimes', 'Elizabeth is lucky to have been the recipient of a large grant', etc. In each case, the sentence is about the present. These cases, we think, prime us to see (a) as partly about the present, rather than wholly about the past.

(a) is a claim about the present. It's a claim about the world being some way, such that it contained dinosaurs. Hold that fixed. Let's now introduce two temporal operators: 'WAS' ('it was the case that') and 'NOW' ('it is now the case that'). We then add the reasonably uncontroversial claim, made by Prior ([1968: 113]; see, for example, axioms J1 and J2), that, where ' $\mathrm{J}$ ' stands for the NOW operator: $\phi \equiv \mathrm{J} \phi$. Simply, for an expression, $\phi$, that expression is true iff it is now the case that it's true.

Return to (a) and (b). We said that it's natural to see that (a) is at least in part about the present: the world is presently some way-it contained dinosaurs. Now turn to (b). Note that 'the world was such that it contains dinosaurs' is true iff it's now the case that the world was such that it contains dinosaurs; 'the world was such that it contains dinosaurs' is logically equivalent to this:

(c) It's now the case that the world was such that it contains dinosaurs.

Contingently true expressions that are logically equivalent share meaning. At least, we think that's correct. (Mathematical truths might be logically equivalent, but they are necessarily true and so don't constitute a counterexample.)

Suppose that's right-we consider challenges, below. (a) is partly about the present. Prima facie it might seem that (b) isn't, that (b) is about the past. But once we note that (b) is logically equivalent to (c), matters become less certain, for (c) is present-tensed. It says that some state is now the case: it's now the case that the world was such that: it contains dinosaurs. Thus, (c) is at least partly about the present. To that extent, we shouldn't be troubled by postulating present truth-makers for truths about the past; we can resist the aboutness concern. Premise $\left(1^{\prime}\right)$ is false.

We anticipate this objection: '(a) isn't about the present. Clearly, "The world is now such that it contained dinosaurs" is about the past. I have no intuition that (a) is about the present; just as (b) is intuitively about the past, so (a) is intuitively about the past. Hence, the defence of Lucretianism is flawed. Similar remarks go for (c).'

Things now become muddy. The notion of aboutness is unclear. No one in the truthmaking literature has given a complete method for determining what a proposition is about. (McDaniel [2011] suggests options; Merricks [2011] argues against them.) Here's the way in which aboutness arguments play out in the literature: someone asserts that it's clear that some proposition isn't about some particular entity and

\footnotetext{
${ }^{5}$ (b) might appear ungrammatical or awkward. But, in departing from ordinary spoken English, it's a way for presentists to interpret perspicuously < dinosaurs existed $>$ or $<$ the world contained dinosaurs $>$ with primitive tense operators entering the story (cf. Sider [2006: 78]). Below, we introduce such operators.
} 
then uses this to reject some philosophical position. But our opponent shouldn't proceed in this way. We say that (a), (b), and (c) are about the present. We think that this is intuitive enough. <The world is now such that it contained dinosaurs > isn't merely about the way that things were; it's also about how they are. We aren't trying to persuade our opponent to adopt Lucretianism; we aim to defend Lucretianism, not to generate converts. So, we close with a challenge. We say that premise (1') is false: past-tensed truths are partly about the present. We've explained why we think that's reasonable. Our opponent here ought not simply to say 'We disagree.' They should say 'You are wrong because___' (and fill-in the blank). Without their filling-in the blank, we don't see that Lucretianism has an obvious case to answer.

There's scope to consider another challenge. We presented the second premise as this:

$\left(2^{\prime}\right)$ If $P$ isn't about the present, $P$ cannot have present truth-makers.

Perhaps that isn't right. Perhaps, says our opponent, we should adopt this:

$\left(2^{\prime \prime}\right)$ If $P$ is about the past at all, $P$ should be made true by the past.

This would undermine our position.

However, $\left(2^{\prime \prime}\right)$ is too strong. It appears to be a specific instance of a general principle: if $P$ is about $\mathrm{x}, P$ should be made true by $\mathrm{x}$. But there are myriad cases that speak against it. For instance, arch truth-maker theorist Cameron [2010] states that propositions about composite objects could be made true by mereological simples not composites (and he makes similar claims about other truth/truth-maker pairs). Further, nominalists might say that $<\mathrm{x}$ is $F>$ is true, and intuitively about something's being $F$; nonetheless, $\mathrm{x}$ itself is an adequate truth-maker. Perhaps there's an aboutness objection here. But, if there is, the principle and its instance $\left(2^{\prime \prime}\right)$ require defence.

Our opponent might concede that $\left(2^{\prime \prime}\right)$ is too strong, and look to defend a slightly different principle. They might try to insist that, since past-tensed propositions are partly about the past, such propositions must be made true partly by the past. In lieu of $\left(2^{\prime \prime}\right)$, we should thus adopt the following:

$\left(2^{\prime \prime \prime}\right)$ If $P$ is partly about the past (and partly about the present), $P$ should be made true partly by the past (and partly by the present).

If this is correct (that is, if this is a good aboutness constraint), this would undermine our position.

However, this is still too strong-and for the same reason as $\left(2^{\prime \prime}\right)$ was. To illustrate, consider again the nihilist case. Intuitively, it seems plausible that propositions about composite objects are partly about mereological simples and so are partly made true by them. Yet propositions about composites are intuitively also about composites (and not merely about simples). If we generalise $\left(2^{\prime \prime \prime}\right)$, we find that, since true propositions about composites are partly about the composites (and partly about the simples), they should be made true partly by composites (and partly by simples). In that case, if $\left(2^{\prime \prime \prime}\right)$ is correct, then Cameron's view should (but does not) face an aboutness objection. So much the worse for $\left(2^{\prime \prime \prime}\right)$. Similar remarks can be made in the nominalist case. $<\mathrm{x}$ is $F>$ is partly about $\mathrm{x}$ and partly about its being $F$, so $<\mathrm{x}$ is $F>$ should be made true partly by $\mathrm{x}$ and partly by $F$, if $\left(2^{\prime \prime \prime}\right)$ is correct. Put differently, if $\left(2^{\prime \prime \prime}\right)$ is 
correct, the nominalist should (but does not) face an aboutness objection. Again, so much the worse for $\left(2^{\prime \prime \prime}\right)$.

\section{Improper Explanations}

Sanson and Caplan [2010] (hereafter, 'S\&C') object that Lucretian truth-makers don't provide 'proper' explanations. S\&C invite us to consider the true proposition, $A$, that Arnold was pale. Suppose that a putative truth-maker for $A$ is Arnold (for simplicity) and his instantiating the property, having been pale. More formally, borrowing from S\&C [ibid.: 26], we have the following explanation:

(Present) $A$ is true because Arnold now exemplifies having been pale.

S\&C argue that (Present) isn't a 'proper' explanation of the truth of $A$. To illustrate, compare (Present) to a rival explanation [ibid.]:

(Past) $A$ is true because Arnold once exemplified being pale.

S\&C assert that (Past) is preferable to (Present). Suppose that all evil in the world is due to Satan. For S\&C, the Lucretian position is like trying to explain the world's evil by appealing to $\{$ Satan\}-namely, Satan's singleton-rather than to Satan. There's a sense in which \{Satan\} explains the evil in the world, they suggest, but only because $\{$ Satan\} includes Satan as a member. Similarly, there's a sense in which Arnold's instantiating having been pale explains the truth of $A$. But the explanation is worse than that given by Arnold's having had being pale.

This is important: the truth-making project is one in which the truth of propositions is explained. For instance, Cameron [2018: 333] tells us that 'truthmakers are the ontological ground of the truth; their existence explains why the proposition in question is true', and McFetridge [1990: 42] remarks that truth-maker theory expresses 'the thought that for every sentence that is true there must be some explanation of why it is true'. The theory requires us to provide truth-makers that explain why propositions are true. Thus, there is a challenge: Lucretian truth-makers must but don't explain the truth of propositions for which they are putative truth-makers.

S\&C's objection fails. To see why, here's Cameron with some more detail on what truth-maker theorists mean by 'explanation' [2018: 333, emphasis added]:

[It] is true that there were dinosaurs. Why? The truthmaker theorist says we can't just take this historical fact as brute-we must provide an ontological explanation for its truth: there must be some things that make it the case that there were dinosaurs, whose existence explains why the historical facts are as they are in this respect. Truth doesn't come for free, it must be grounded in ontology - that is the truthmaker theorist's thought.

Truth-maker theorists think that the explanation of why a (true) proposition is true is a fact about what exists. The truth of $P$ is to be explained, and that explanation bottoms out in an existential proposition (that starts with 'there exists some $\mathrm{x}$, such that ...'). That's what an ontological explanation of a truth is. The challenge for presentists is to provide ontological explanations for the truth of propositions about the past when 'obvious' ontological explanations aren't available to them.

If we take the challenge seriously, S\&C are wrong. (Past) can't ontologically explain the truth of $A$, when deployed by presentists, because it doesn't mention something that exists. It merely states that something existed. If the truth-maker theorist is right, if we 
require an ontological explanation for the truth of $A$, then (Past) gives us nothing of value. We thus suggest that $\mathrm{S} \& \mathrm{C}$ are wrong to think that (Past) gives us a better explanation of the truth of $A$ than (Present), because only (Present) gives us an ontological explanation of $A$ 's truth.

But one might take S\&C to be arguing against truth-maker theory at this stage. They can concede that only (Present) gives us an ontological explanation, yet argue that (all things considered) it's better to treat (Past) as the proper explanation for $A$ 's truth and, as a consequence, to give up the search for ontological explanations for the truth of propositions about the past. If (Past) is the best explanation simpliciter, perhaps we shouldn't be looking for truth-makers for truths about the past.

Perhaps. Certainly, it's a route explored (for instance, by Merricks [2007] and Tallant [2009]). But the question of whether to provide truth-makers for truths about the past isn't our issue. We engage in an 'upstanding' spirit. Within that context, we defend Lucretianism as a way of providing ontological explanations. The question of whether to try to provide ontological explanations must be tackled elsewhere.

\section{Necessary Connexions}

Baron [2013a] charges that presentists cannot address the truth-maker objection by positing present truth-makers because such an approach is 'self-defeating'. Baron notes that if the world was some way, then, necessarily, the world now instantiates certain tensed properties. Put generally, there's a modal connection between how things were and how things are. Here's one example: Marie Curie discovered Polonium; so, necessarily, the world now instantiates the Lucretian property, having contained Curie discovering Polonium. If, per impossible, the world fails to instantiate having contained Curie discovering Polonium, then we have a case in which Curie discovered Polonium but $<$ Curie discovered Polonium $>$ isn't true (now): there's no present truthmaker, the Lucretian property isn't instantiated, and so the proposition isn't true [ibid.: 8-9].

Baron thinks that we can enshrine this idea in a general principle. Allow that 'the Fs' are present Lucretian properties and 'the Ss' are things that existed. Baron suggests that presentists should endorse 'N1': necessarily, the Fs exist or are instantiated only if the Ss existed or occurred [ibid.: 9]. But presentists cannot endorse N1, says Baron, because it implies an unacceptable connection between past and present [ibid.: 11]:

\footnotetext{
[Most] presentists ... believe that past things cannot be the relata in any relations, because (i) all relations are existence entailing ... and (ii) the past does not exist. ... [Presentists] cannot accept the existence of necessary connections between the Fs and the Ss ... [If] one is going to allow cross-temporal modal connections of the kind needed for necessitation, then there is no longer anything objectionable about cross-temporal supervenience in particular.
}

Baron concludes that the presentist truth-maker theorist (an 'upstanding' presentist) is in trouble [ibid.: 11-2]. He doesn't schematise the argument, but the idea seems to be this:

(1) N1 requires a 'necessary connexion' between the past and present.

(2) A necessary connexion is a relation.

(3) Relations are existence-entailing; a relation exists only if its relata exist.

(4) There exist no past things whatsoever, given presentism. 
(5) Therefore, there exist no relations between the past and present (From 3, 4)

(6) Therefore, N1 is false (From 1,5)

We think that Lucretians should deny (1).

Consider a presentist description of a sequence of events where it's necessary that $e_{1}$ precedes $e_{2}$ and where $e_{2}$ is (now) present. To say that such a progression is necessary, we begin with a modal operator. We then say this: ' $e_{2}$ exists now' only if $e_{1}$ existed. Altogether: necessarily, $e_{2}$ exists only if $e_{1}$ existed. As we judge it, there's nothing unintelligible about this claim. Further, we don't require the existence of a further entity, a relation, between $e_{2}$ and $e_{1}$. Presentists can (and should) make similar claims about the way that the world was and the Lucretian properties that it now instantiates.

There is thus no more to be said over and above N1. There is no thing that is a connexion between the Fs and Ss. There's no relation that stands between how things were and are, such that its 'existence-entailing' nature generates a problem. Nonetheless, it's necessary that if the Fs exist then the Ss existed or occurred.

Baron [2013a] thus misconceives of what's required. Presentists don't talk of there being past things (the Ss) such that these things are connected to present instantiations of Lucretian properties (the Fs). There exist no past things at all. Sentences like N1 express all the necessity required. It's necessary that a Lucretian property is now instantiated if certain things existed or occurred. But what makes it true that <certain things existed $>$ is no more than the property. So, there's a connexion between two truths: $<$ Curie discovered Polonium $>$ and $<$ there are Lucretian properties that 'make true' $<$ Curie discovered Polonium $>>$. It's therefore neither surprising nor problematic that there's a necessary connexion between such truths. ${ }^{6}$

Perhaps there's another way to understand our opponent's concern. We provide a necessary connexion between two truths, $<e_{1}$ existed $>$ and $<$ the world now instantiates having contained $\mathrm{e}_{1}>$, by stipulating that they have the same truth-maker. But more is needed, says our opponent: we need a connexion between what existed, $e_{1}$, and what exists now, such as the world (@) instantiating the relevant property. For all that's said, we haven't provided that connexion.

We agree: we don't provide that. We don't think that we need to do so. It's true that @ contained $e_{1}$. It's true that @ cannot be such that $<@$ contained $e_{1}>$ is true and that $<@$ now instantiates having contained $\mathrm{e}_{1}>$ is false. Suppose that we're at time $t^{*}$ and $<e_{1}$ existed (at $t)>$ is true. What makes it true is that $e_{1}$ existed. The same truth-maker goes for $<e_{1}$ existed exists $>$. Since the two share a truth-maker, $<e_{1}$ might not have existed in cases where $e_{1}$ existed exists $>$ is false.

Our opponent might say 'Isn't it possible that @ could have failed to contain $e_{1}$ ?' We think so. It's possible that @ could have been other than it is. But that's a simple modal fact that will be accounted for by whatever means by which we ground modal truths. If our opponent says 'Isn't it possible that @ didn't contain $e_{1}$ even though @ now instantiates having contained $\mathrm{e}_{1}$ ?' No, because if @ now instantiates having contained $\mathrm{e}_{1}$, then $<@$ didn't contain $e_{1}>$ cannot be true. After all, the truth-maker for $<@$ contained $e_{1}>$ exists. Put simply, our opponent hasn't located a truth about the past that's in tension with how the world is now. Our opponent needs to locate a truth about the past with which Lucretians cannot agree.

${ }^{6}$ Leininger [2015: 732-5] presses a similar objection. We don't review this objection, or present it separately, since it's based on the same basic premise (i.e. that an existence-entailing relation holds between past and present). 


\section{Primitives and Entailment}

McKinnon and Bigelow [2012] (hereafter, 'M\&B') raise two connected worries for the Lucretian. They treat Lucretian properties as instantiated by individuals in the world, rather than by the world. Suppose, then, that Elise currently instantiates the property having been a mother. It's obvious that she has instantiated being a mother. Following $\mathrm{M} \& \mathrm{~B}$, suppose that being a mother is primitive and unanalysable. It seems to follow that having been a mother is also primitive and unanalysable. More worryingly, it seems that having been a mother cannot be analysed in terms of being a mother. After all, what form could this analysis take? We cannot treat having been a mother as a relational property, analysable as being a mother and existing in the past. No presentist can admit that there's an instantiated property existing in the past. It appears, say M\&B, that Lucretianism is thereby committed to properties like having been a mother as primitive and unanalysable [ibid.: 256].

M\&B think that this troubles the Lucretian for two reasons. First, it looks like we must postulate myriad primitive Lucretian properties. That is, '[take] any primitive property, and its past-tensed correlate looks like it also needs to be primitive' [ibid.]. Since we generally prefer not to posit primitive properties, it's a bad result for Lucretianism if it posits so many. Second, there seems to be an unexplained 'connection' between Elise's instantiating being a mother and later instantiating having been a mother. After all, that she instantiates one entails that she will instantiate the other. But how can we explain this entailment? We must, of course, if we dislike unexplained necessary connexions between distinct existents. (We might wish to be good Humeans, after all.)

We offer an analysis of Lucretian properties according to which only a few primitive properties are invoked (section 5.1), add a model of thisnesses defended elsewhere in the literature, and give a semantics to enable us to understand the metaphysics (section 5.2). In doing so, we also reply to Orilia's [2016] objection that some Lucretian properties commit us to past entities. Finally, we deny that there's any entailment of the form suggested (section 5.3). This gives Lucretians the tools with which to resist these concerns.

\subsection{On Lucretian Properties}

We start with the metaphysics. Here we focus on Lucretian properties as instantiated by the world, as per Bigelow [1996]. (It's the full Lucretian position that we defend, not merely the properties.) Recall that Lucretian properties, as specified by Bigelow, are of the form 'having contained such-and-such'. We think that, as there are past-tensed properties, so there are present-tensed properties of the form 'containing such-andsuch'. (We set aside future-tensed properties.) In this section, we focus on simple cases involving Lucretian properties; we consider more complex cases in section 5.2. We stipulate that the Lucretian metaphysic deploys states of affairs as truth-makers -we refer to them as 'facts' from here onward. This choice is hardly novel (see, for instance, Armstrong [2004]), although it might be controversial. However, we don't see that this must be unduly costly. Note that, dialectically, there's supposed to be something distinctively objectionable about Lucretian properties. Given the ties between the truth-making project generally and facts, it's unsurprising that the two are natural bedfellows. Second, we don't say that 'non-fact' versions of our view must fail There's a rich history of other positions - that is, substance/attribute theory, trope theory, etc.-being 
used to do similar work. Perhaps that can be done here. We don't explore these options since ours is only a defence of Lucretianism's viability. If the worst that can be said is that Lucretianism requires a 'fact-metaphysic' to solve truth-maker worries, we rest content.

Let's begin by describing some resources. The world, @, now contains objects being particular ways. Thus, we suppose, @ stands in the relation containing to various things. We treat containing as a primitive, relational, and abundant property. It can be analysed. To say that @ contains is to say that there's at least one thing that exists within @. There's nothing mysterious about the notion. Talk of '@ containing ...' is contrived and stylised, but this is unimportant. It's perfectly grammatical to say that an object 'is containing such-and-such' (simply think of a full kettle containing water). So, we can allow that there's a perfectly comprehensible property, containing, to which that predicate corresponds. To this we add another relational property. It is the property having contained. This is a primitive, past-tensed version of the property containing. Finally, we accept that there are properties such as being a mother. This is M\&B's own assumption. All of this together allows us to reply to M\&B.

If all that the Lucretian wishes to say is that $<$ the world once contained a mother $>$ is true, then a perfectly adequate truth-making fact might consist of the world, @, as thin particular, standing in the having contained relation, $\mathrm{H}$, to the property being a mother, M: H[@, M]. The end result would be parsimonious. The only new primitive unanalysable property is having contained. Everything else is analysable. However, our reply to $\mathrm{M} \& \mathrm{~B}$ isn't yet complete. Into the mixture, we add thisnesses (haecceities). ${ }^{7}$ That's the focus of our next section.

\subsection{Individuals and Thisnesses}

Let's return to the story of Elise, amended with the caveat that she doesn't exist now (she has ceased to exist). If Elise doesn't exist, she cannot be a part of an existing truthmaking fact. Thus, our story requires development. Keller [2004: 96-101] suggests two options-thisnesses of past individuals or sempiternal atoms. We follow M\&B in putting thisnesses to work, although we're more optimistic about their prospects.

Elise doesn't exist, but she existed. When she existed, she instantiated propertiesfor example, being an organism, being a mother, being Elise, and so on. The property, being Elise, is Elise's thisness-namely, the non-qualitative property of being identical with that individual. This property is something like an individual essence; Elise instantiates it uniquely throughout her existence. Elise's thisness doesn't precede her -it doesn't (cannot) exist before she exists-but the thisness continues to exist uninstantiated after Elise has ceased to exist (see Adams [1986] and Ingram [2019] for details). On this view, a thisness can exist uninstantiated. This is the view of thisnesses that we adopt, since it's acceptable to presentists (pace Markosian [2004: 55-6]; for a reply to Markosian, see Ingram [2016: 2879-80]). Our complete metaphysical proposal can then be stated.

Truths about the past are made true by the state of affairs (fact) of the world, @ (with all of its other properties - use ' $\mathrm{F}$ ' to stand for these), standing in the relational property

\footnotetext{
${ }^{7}$ Following our point about parsimony, we recognise that the addition of thisnesses is a further cost. But, plausibly, it's a cost required by presentism, as M\&B note [2012: 259-60], as Keller [2004: 96-9] suggests, and as Ingram [2019] argues.
} 
having contained to the fact of a thisness instantiating specific properties. ${ }^{8}$ For example, $<$ Elise was a mother $>$ is made true by the complex fact of @ standing in the relational property having contained to the fact of Elise's thisness, T, instantiating being a mother. Thus, H [@, F], [T, M]. This might seem strange. To highlight the strangeness, we borrow Keller's [2004] example of being executed as instantiated by Anne Boleyn's thisness-being Anne Boleyn. What does it mean to say that a thisness instantiates being executed? Keller correctly notes that you can execute a person, not a property [ibid.: 97]. Thisnesses are properties and, given their natures, there are lots of things that properties cannot be. With this in mind, we appear to face a problem (or, at least, some strangeness). We say that Elise's thisness instantiates being a mother and, of course, properties can't be mothers. Prima facie, it appears that we're committed to the truth of $<$ Elise's thisness is a mother $>$, and that's objectionable.

We reject this apparent commitment. Thisnesses (properties, generally) can't be mothers, can't be executed, etc. A thisness cannot be a mother (nor can the fact into which it's embedded), but that's no barrier to instantiating being a mother. For this to work, we must be flexible with the semantics provided. In what follows, we sketch a semantics for tensed predication that couples neatly with the metaphysic outlined above.

Lucretians should adopt the following tensed truth-conditions:

(is now) A present-tensed sentence of the form 'a is (now) F' is true iff there exists a fact of the form $[\mathrm{a}, \mathrm{F}]$ and a's thisness instantiates being $F$.

(was) A past-tensed sentence of the form 'a was F' is true iff there exists a fact of @ standing in the relational property having contained to the fact of a's thisness being $F^{9}{ }^{9}$

Given these truth-conditions, $<$ Elise was a mother $>$ is true. It's made true by the following complex fact: $\mathrm{H}[@, \mathrm{~F}],[\mathrm{T}, \mathrm{M}]$. This is the correct result. ${ }^{10}$

Now, there exists a fact that Elise's thisness, T, instantiates being a mother. Does it follow that $<\mathrm{T}$ was a mother $>$ is true? No. That proposition is false on our analysis. $<\mathrm{T}$ was a mother $>$ is true iff there exists a fact of @ standing in the relational property having contained to the fact of T's thisness instantiating being a mother. And T's thisness doesn't instantiate that property. Recall that T is a thisness; T's thisness is the thisness of a thisness. Perhaps T's thisness exists, but there's no reason to suppose that it instantiates being a mother. After all, Lucretians will say that $\mathrm{T}$ instantiates being a mother because Elise was a mother. By analogous reasoning, T's thisness doesn't instantiate being a mother because T never was a mother. Equally, it doesn't follow that $<\mathrm{T}$ is a mother $>$ is true. Although there exists the fact that $\mathrm{T}$ instantiates being a mother, $<\mathrm{T}$ is a mother $>$ is false. That proposition $(<\mathrm{T}$ is a mother $>)$ is true iff there exists a fact

\footnotetext{
${ }^{8}$ This isn't the line taken by Ingram [2019], who uses thisnesses instantiating Lucretian properties to respond to the truth-maker objection. Ingram's story about Lucretian properties instantiated by thisnesses is distinct from ours. We don't claim that ours is the only way to go; we aim to address the challenge(s) from M\&B [2012], whereas Ingram doesn't engage with them.

${ }_{9}<$ a was $\mathrm{F}>$ is a past-tensed proposition about a particular. We assume that the truth of more general claimse.g. <there were dinosaurs >- will supervene on the truth of propositions about particulars. This is no more than a generalisation of the idea that the truth of $<$ there are people $>$ supervenes on the truth of $<x$ is a person and $x$ exists $>$, for some specific instance of $x$. Here we adopt a semantics for the past-tense that largely replicate Ingram's [2019: 128-34]; see therein for discussion and defence.

${ }^{10}$ We don't think that the semantics sketched are the only option for a Lucretian. But we think that the semantics work, and, thus that Lucretianism can avoid M\&B's objection. Another option, inspired by Plantinga [1974] and suggested by a reviewer, is to state that, for example, the world contained $E T$ co-instantiated with being a mother.
} 
of the form [T, M] and T's thisness instantiates being a mother. Once again, T's thisness doesn't instantiate that property.

A further objection suggests itself. The semantics are spuriously ad hoc. An objector might contend that, faced with an otherwise intractable objection, we 'cut from whole cloth' a way to understand the truth-conditions of tensed sentences, solely with the intention of 'patching up' Lucretianism. And that won't do. To believe that the truthconditions are apt, we should be provided with some good reason. Ideally, that reason would be independent of Lucretianism.

We don't think that this objection hits home. Ours is certainly a case where analysis outstrips intuition. But comparison with other cases leaves us comfortable with the idea that there's no threat. For instance, consider the semantics for modal claims provided by some fictionalists: ' $<\diamond p>$ is true iff, according to the fiction of possible worlds, $p$ is true at some world' [Nolan 2016: sec. 1]. It strikes us that, independently of motivations for endorsing modal fictionalism, there's no reason to think that the stated truth-conditions for modal claims are correct. There's no independent reason to think that the fictionalist semantics accurately reflect the truth-conditions of modal discourse. But that's fine. The fictionalist spells out their metaphysical commitments, and then explains how to understand them by using a particular account of the truth-conditions for modal claims. Provided that those semantics are fit for purpose (something well-discussed in the literature on fictionalism: see Nolan [2016] for an overview), the fictionalist is untroubled. Matters are the same for Lucretianism. The place for opponents to apply pressure is on the analysis of the truth-conditions provided. Are they fit for purpose? If not, Lucretianism must either be patched or rejected.

Now we turn to an objection to Lucretianism from Orilia [2016: 600]. On the standard Lucretian story, the truth-maker for (for instance) <Elise was a mother $>$ is @ now instantiating having contained Elise being a mother. Or, in our terms, it is @ standing in the relational property having contained to Elise being a mother. But @ cannot stand in this relationship with Elise; Elise doesn't exist.

This issue can be resolved briefly; we addressed a version of it above. On our story, the Lucretian accepts thisnesses of wholly past individuals, not the past individuals themselves.

We reiterate our proposal to show how we respond to Orilia's objection and to address a concern. Our proposal involves thisnesses. But once presentists accept thisnesses, what work remains for the Lucretian metaphysic? If presentists must accept thisnesses, why not accept Keller's haecceitist presentism or Ingram's thisness presentism instead?

In response, we note that much of our paper is a defence of Lucretian properties. And, since the likes of Ingram also posit such properties, we don't see our positions as entirely opposed. Even so, our project is to rehabilitate Lucretianism; we say nothing to defend other views or to say that the Lucretian view is better than views defended by the likes of Ingram and Keller. It's possible (we think it is quite likely) that all that we've said here to defend Lucretianism can be extended to other thisness views-for example, Ingram's thisness presentism. But that isn't work that we've done here.

\subsection{Unexplained Entailments}

Next is M\&B's concern about unexplained entailments. We begin with a reminder: the fact that Elise instantiates being a mother at some time is supposed to entail that she instantiates having been a mother at later times. That @ instantiates containing $a$ 
mother entails that it will instantiate having contained a mother. How can we explain this entailment?

The answer is that we don't. There's no entailment. The world can instantiate containing a mother without later instantiating having contained a mother. To illustrate, suppose that@ instantiates containing a mother at the last moment of time. In that case, it's not true that @ instantiating containing a mother entails that it will instantiate having contained a mother. It's (metaphysically) possible that every moment is the last moment of time, and so there are no entailments of the sort that M\&B describe. Therefore, there's no objection to Lucretianism.

Our opponent might reply thus: necessarily, if $t$ isn't doomsday, and Elise instantiates being a mother, then she will instantiate having been a mother at some later time(s). And this, the opponent might say, is just as problematic. We disagree. We maintain that, for Lucretians, temporal passage has two components. First, passage consists in various entities coming into being. Second, though speaking somewhat loosely, @ changes from containing particular facts involving $\mathrm{F}$ to having contained those particular states of affairs involving $\mathrm{F}$ (for any F). That's what temporal passage is for Lucretians. Our opponent then asks for an account of why, if time passes, that entails that @ must change from containing some $F$ to having contained $F$. But if we accept the Lucretian account of what passage is, then we are being asked why, if @ changes from containing $F$, to having contained $F$, this entails that @ changes from containing $F$, to having contained F. And that's easy enough to explain. The entailment holds because it's a tautology.

\section{Dated Truths and Metric Properties}

Here is a final objection. For Orilia [2016: 600-1], the putative truth-makers are at best sufficient for undated tensed truths-for example, <Elise was a mother $>$ (' $u$ ') - but insufficient for dated truths-for example, <Elise was a mother on 10 June, 1987> (' $d$ '). The truth-maker for $u$ cannot be an adequate truth-maker for $d: u$ is made true by @ standing in the relational property having contained to Elise's thisness, ET, instantiating being a mother, but this truth-maker doesn't 'discriminate' between a truth, $d$, and falsehoods-for example, <Elise was a mother on 22 May, 1947> [ibid.: 600].

Orilia mentions and dismisses one remedy-that is, that the Lucretian accepts metric tensed properties, such as being a mother 35 years ago [ibid.: 601]. At first pass, the remedy is effective. Suppose that @ stands in the relational property having contained to ET instantiating being a mother 35 years ago. This is a truth-maker for $d$, not any falsehoods. However, Orilia objects that this truth-making story violates a 'no shifting' intuition, according to which the truth-maker of a truth 'should not change in time' [ibid.]. It isn't controversial that truth-makers involving metric properties will change. For example, in 10 years, the truth-maker for $d$ can't be that @ stands in the relational property having contained to ET instantiating being a mother 35 years ago; it must be that @ stands in the relational property having contained to ET instantiating being a mother 45 years ago.

We agree that Lucretianism must incorporate metric properties to provide an adequate account of truth-makers for truths about the past. But we don't feel the pull of a 'no shifting' intuition and nor should the Lucretian. Consider <Annie was hungry $>$ and suppose that Annie was hungry (5 minutes ago). Now, suppose that a minute passes. The proposition is still true, but now it's true because Annie was hungry six 
minutes ago (not because she was hungry five minutes ago). Even in folk-terms, this is how to explain why $<$ Annie was hungry $>$ is true. The Lucretian reflects that in their metaphysic. At one time, what makes true <Annie was hungry $>$ is that @ stands in the relational property having contained to Annie's thisness, AT, instantiating being hungry (five minutes ago). At the later time, what makes the proposition true is that @ stands in the relational property having contained to AT instantiating being hungry (six minutes ago). Hence, there's nothing objectionable or problematic about truth-makers changing in the way described.

\section{Conclusion}

Lucretianism hasn't proven popular, but the objections don't stick. We don't think that this implies that Lucretianism is flawless or even true. Nonetheless, opponents must do better. $^{11}$

\section{Disclosure Statement}

No potential conflict of interest was reported by the author(s).

\section{References}

Adams, Robert 1986. Time and Thisness, Midwest Studies in Philosophy 11: 315-29.

Armstrong, D.M. 2004. Truth and Truthmakers, Cambridge: Cambridge University Press.

Baron, Sam 2013a. Presentism, Truth and Supervenience, Ratio 26/1: 3-18.

Baron, Sam 2013b. Talking About the Past, Erkenntnis 78/3: 547-60.

Bergmann, Michael 1996. A New Argument from Actualism to Serious Actualism, Nô̂s 30/3: 356-9. Bergmann, Michael 1999. (Serious) Actualism and (Serious) Presentism, Noûs 33/1: 118-32.

Bigelow, John 1996. Presentism and Properties, Philosophical Perspectives 10/1: 35-52.

Butterfield, Jeremy 1984. Seeing the Present, Mind 93/370: 161-76.

Cameron, Ross P. 2008. How to Be a Truthmaker Maximalist, Noûs 42/3: 410-21.

Cameron, Ross P. 2010. How to Have a Radically Minimal Ontology, Philosophical Studies 151/2: 249-64.

Cameron, Ross P. 2011. Truthmaking for Presentists, Oxford Studies in Metaphysics, Vol. 6, ed. Karen Bennett and Dean Zimmerman, Oxford: Oxford University Press: 55-100.

Cameron, Ross P. 2018. Truthmakers, in The Oxford Handbook of Truth, ed. Michael Glanzberg, Oxford: Oxford University Press: 333-54.

Chisholm, Roderick 1990. Events Without Times: An Essay on Ontology, Noûs 24/3: 413-27.

Crisp, Thomas 2007. Presentism and the Grounding Objection, Noûs 41/1: 90-109.

Hinchliff, Mark 1988. A Defense of Presentism, Ph.D. dissertation, Princeton University.

Ingram, David 2016. The Virtues of Thisness Presentism, Philosophical Studies 173/11: 2867-88.

Ingram, David 2019. Thisness Presentism: An Essay on Time, Truth, and Ontology, London: Routledge.

Keller, Simon 2004. Presentism and Truthmaking, Oxford Studies in Metaphysics, Vol. 1, ed. Dean W.

Zimmerman, Oxford: Oxford University Press: 83-104.

Leininger, Lisa 2015. Presentism and the Myth of Passage, Australasian Journal of Philosophy 93/4: 724-39.

Markosian, Ned 2004. A Defense of Presentism, Oxford Studies in Metaphysics, Vol. 1, ed. Dean W. Zimmerman, Oxford: Oxford University Press: 47-82.

McDaniel, Kristopher 2011. Trenton Merricks' Truth and Ontology, Philosophy and Phenomenological Research 83/1: 203-11.

McDaniel, Brannon 2014. A Defense of Lucretianism, American Philosophical Quarterly 51/4: 373-85.

${ }^{11}$ We are grateful to two anonymous reviewers for comments and suggestions that helped to improve the paper. We are also grateful to the Editor for advice and support throughout the review process. 
McFetridge, Ian 1990. Truth, Correspondence, Explanation and Knowledge (1977), in Logical Necessity and Other Essays, ed. John Haldane and Roger Scruton, London: Aristotelian Society: 29-52.

McKinnon, Neil and John Bigelow 2012. Presentism, and Speaking of the Dead, Philosophical Studies 160/2: 253-63.

Merricks, Trenton 2007. Truth and Ontology, Oxford: Oxford University Press.

Merricks, Trenton 2011. Replies, Philosophy and Phenomenological Research 83/1: 212-33.

Miller, Kristie 2013. Presentism, Eternalism, and the Growing Block, in A Companion to the Philosophy of Time, ed. Heather Dyke and Adrian Bardon, Malden, MA: Wiley Blackwell: 345-64.

Nolan, Daniel 2016. Modal Fictionalism, The Stanford Encyclopedia of Philosophy (Spring 2016), ed. Edward N. Zalta, URL = https://plato.stanford.edu/archives/spr2016/entries/fictionalism-modal

Orilia, Francesco 2016. Moderate Presentism, Philosophical Studies 173/3: 589-607.

Plantinga, Alvin 1983. On Existentialism, Philosophical Studies 44/1: 1-20.

Price, Huw 2011. The Flow of Time, in The Oxford Handbook of Philosophy of Time, ed. Craig Callender, Oxford: Oxford University Press: 276-311.

Prior, A.N. 1968. 'Now', Noûs 2/2: 101-19.

Putnam, Hilary 1967. Time and Physical Geometry, The Journal of Philosophy 64/8: 240-7.

Rodriguez-Pereyra, Gonzalo 2005. Why Truthmakers, in Truthmakers: The Contemporary Debate, ed. Helen Beebee and Julian Dodd, Oxford: Clarendon Press: 17-31.

Routley, Richard 1980. Exploring Meinong's Jungle and Beyond: An Investigation of Noneism and the Theory of Items, Canberra: Research School of Social Sciences, Australian National University

Sanson, David and Ben Caplan 2010. The Way Things Were, Philosophy and Phenomenological Research 81/1: 24-39.

Sider, Theodore 2001. Four-Dimensionalism: An Ontology of Persistence and Time, Oxford: Clarendon Press.

Sider, Theodore 2006. Quantifiers and Temporal Ontology, Mind 115/457: 75-97.

Stephanou, Yannis 2007. Serious Actualism, The Philosophical Review 116/2: 219-50.

Tallant, Jonathan 2009. Ontological Cheats Might Just Prosper, Analysis 69/3: 422-30.

Tallant, Jonathan 2013. Dubious by Nature, Canadian Journal of Philosophy 43/1: 97-116.

Tallant, Jonathan and David Ingram 2015. Nefarious Presentism, The Philosophical Quarterly 65/260: $355-71$. 